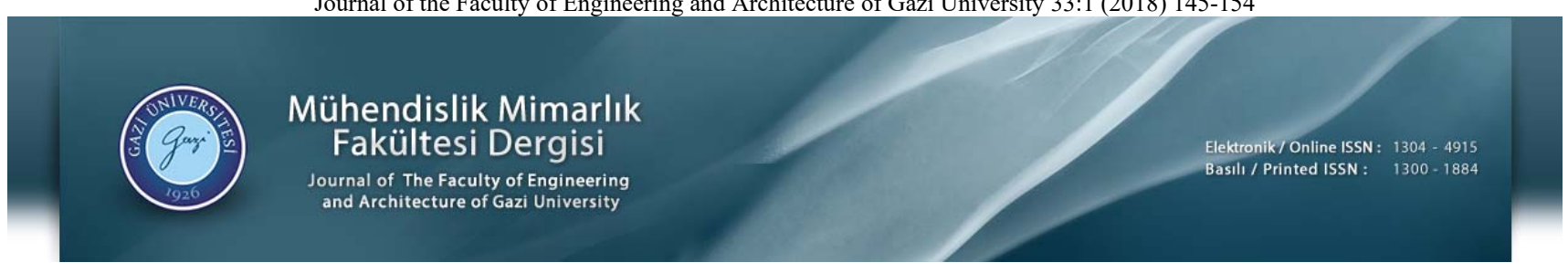

\title{
Zn-15Al-3Cu-1Si alaşımı ve SAE 660 bronzunun yağlı durumdaki aşınma karakteristikleri
}

\author{
Ali Paşa Hekimoğlu ${ }^{1 *(D)}$, Temel Savaşkan² (iD \\ ${ }^{1}$ Recep Tayyip Erdoğan Üniversitesi, Mühendislik Fakültesi, Makine Mühendisliği Bölümü, 53100, Fener, Rize, Türkiye \\ ${ }^{2}$ Haliç Üniversitesi, Mühendislik Fakültesi, Makine Mühendisliği Bölümü, Beyoğlu, İstanbul, 34445, Türkiye

\section{Ö N E Ç I K A N L A R} \\ - $\quad$ Zn-15Al-3Cu-1Si alaşımı SAE 660 bronzuna göre daha yüksek sertlik ve çekme mukavemetine sahiptir \\ - $\quad \mathrm{Zn}-15 \mathrm{Al}-3 \mathrm{Cu}-1 \mathrm{Si}$ alaşımı SAE 660 bronzuna göre daha üstün aşınma direncine sahiptir \\ - Zn-15Al-3Cu-1Si alaşımı kaymalı yatak malzemesi olarak kullanılabilir
}

Makale Bilgileri

Geliș: 23.09.2016

Kabul: 20.12.2016

DOI:

$10.17341 /$ gazimmfd.406787

Anahtar Kelimeler:

$\mathrm{Zn}-15 \mathrm{Al}-3 \mathrm{Cu}-1 \mathrm{Si}$ alaşımı,

SAE 660 bronzu,

sürtünme ve aşınma

\section{ÖZET}

Bu çalışmada $\mathrm{Zn}-15 \mathrm{Al}-3 \mathrm{Cu}-1 \mathrm{Si}$ alaşımının yağlı çalışma koşullarındaki sürtünme ve aşınma davranışları blok-disk tipi bir deney düzeneği kullanılarak incelendi. Sürtünme ve aşınma deneyleri farklı yağ debileri $\left(0,25-3,0 \mathrm{~cm}^{3} \mathrm{~h}^{-1}\right)$, kayma hızları $\left(0,5-3,0 \mathrm{~ms}^{-1}\right)$ ve basınçlarda $(1-8 \mathrm{MPa})$ gerçekleştirildi ve sonuçlar SAE 660 yatak bronzundan aynı koşullarda elde edilen sonuçlarla karşılaştırıldı. Hem çinko esaslı alaşımın hem de bronzun sürtünme katsayılarının artan basınç ve yağ debisi ile azaldığı, ancak kayma hızıyla önemli bir değişim sergilemediği görüldü. Alaşımların çalışma sıcaklıklarının artan yağ debisi ile azalıpartan basınç ve kayma hızı ile arttığı belirlendi. Alaşımlarda aşınma ile meydana gelen hacim kaybının ise artan yağ debisi ile azalıp artan basınçla arttığı, ancak kayma hızından fazla etkilenmediği görüldü. Ayrıca, $\mathrm{Zn}-15 \mathrm{Al}-3 \mathrm{Cu}-$ 1Si alaşımının belirtilen koşullarda SAE 660 alaşımından daha yüksek aşınma direnci sergilediği görüldü.

\section{Lubricated wear characteristics of $\mathrm{Zn}-15 \mathrm{Al}-3 \mathrm{Cu}-1 \mathrm{Si}$ alloy and SAE 660 bronze}

\section{H I G H L I G H T S}

- The $\mathrm{Zn}-15 \mathrm{Al}-3 \mathrm{Cu}-1 \mathrm{Si}$ alloy has higher hardness and tensile strength than SAE 660 bronze

- The $\mathrm{Zn}-15 \mathrm{Al}-3 \mathrm{Cu}-1 \mathrm{Si}$ alloy exhibits much higher wear resistance than SAE 660 bronze

- $\quad \mathrm{Zn}-15 \mathrm{Al}-3 \mathrm{Cu}-1 \mathrm{Si}$ alloy can be used in production of sliding bearings

\section{Article Info}

Received: 23.09 .2016

Accepted: 20.12 .2016

DOI:

10.17341/gazimmfd.406787

Keywords: $\mathrm{Zn}-15 \mathrm{Al}-3 \mathrm{Cu}-1 \mathrm{Si}$ alloy, SAE 660 bronze, friction and wear

\section{ABSTRACT}

In this study, lubricated friction and wear characteristics of $\mathrm{Zn}-15 \mathrm{Al}-3 \mathrm{Cu}-1 \mathrm{Si}$ alloy were investigated using a block-on-disc type test machine. Friction and wear tests were carried out at different oil flow rates $(0.25-$ $\left.3.0 \mathrm{~cm}^{3} \mathrm{~h}^{-1}\right)$, sliding speeds $\left(0.5-3.0 \mathrm{~ms}^{-1}\right)$ and contact pressures $(1-8 \mathrm{MPa})$ and the results were compared with those obtained from SAE 660 bearing bronze under the same test conditions. Friction coefficients of both $\mathrm{Zn}-15 \mathrm{Al}-3 \mathrm{Cu}-1 \mathrm{Si}$ alloy and bronze decreased with increasing pressure and oil flow rate, but showed no significant change with sliding speed. Working temperature of the alloys decreased with increasing oil flowrate, but increased with increasing sliding speed and contact pressure. The wear volume of the experimental alloys decreased with increasing oil flow rate, increased with increasing contact pressure, but showed no considerable change with sliding speed. It was also found that the $\mathrm{Zn}-15 \mathrm{Al}-3 \mathrm{Cu}-1 \mathrm{Si}$ alloy exhibits higher wear resistance than SAE 660 bronze under specified test conditions. 


\section{GIIRIŞ (INTRODUCTION)}

Son yüzyıl içerisinde geliştirilen ZAMAK (Zn-Al-Mg-Cu), ZA (Zn-Al-Cu) ve ALZEN (Al-Zn-Cu) serisi $[1,2]$ çinko esaslı alaşımlar bazı mühendislik uygulamalarında başarıyla kullanılmaktadır [3, 4]. Yapılan inceleme ve değerlendirmeler sonucunda çinko esaslı alaşımların beyaz metal, bronz, pirinç ve dökme demir gibi geleneksel yatak malzemelerine göre bir takım üstünlüklere sahip oldukları görülmüştür $[5,6]$. Bu üstünlüklerin başında söz konusu alaşımların üretimlerinin kolay ve ekonomik olması [7, 8], yüksek aşınma direnci ve özgül mukavemete (mukavemet/yoğunluk) sahip olmaları [9, 10], iyi yüzey kalitesi ede etmeye elverişli olmaları, sert parçacıkları içine alma özelliğine sahip olmaları, yetersiz yağlama durumunda bile ideal tribolojik davranış sergilemeleri $[3,6]$ ve yüksek titreşim sönümleme kapasitesine sahip olmaları gelmektedir $[2,9]$. Çinko esaslı alaşımların üstün tribolojik özellikler sergilemesi $[4,6]$ bunların içyapı ve mekanik özelliklerinin uygun olmasının yanı sıra kullanım sırasında yüzeylerinde oluşan çinko ve alüminyum oksit filmlerine dayandırılarak açıklanmaktadır $[5,11]$.

Şöyle ki, söz konusu alaşımların içyapıları yumuşak birmatris ile bunun içerisinde yer alan sert fazlardan oluşmaktadır. $\mathrm{Bu}$ alaşımların yumuşak matrisleri katı yağlayıcı gibi davranarak kaymayı kolaylaştırırken, matris içerisinde bulunan sert fazlar ise yük taşıma görevi yapmaktadır [12, 13]. Zn-Al esaslı alaşımlar üzerinde yapılan çalışmalar $[14,15]$ bakır içermeleri durumunda bu alaşımların avantajlarının yanı sıra bazı dezavantajlara da sahip olduklarını göstermiştir. Bu dezavantajların başında söz konusu alaşımların dökülmüş durumda boyutsal kararsızlık sergilemeleri, mekanik özelliklerinin sıcaklığa duyarlı ve bazı uygulamalar için yetersiz olması gelmektedir $[14,15]$. Boyutsal kararsızlık problemi, döküm sırasında oluşan bakırca zengin yarı kararlı (metastabil) $\varepsilon$ fazının [16] alaşımların kullanımı sırasında kararlı fazlara dönüşmesinden kaynaklanmaktadır [15, 17]. Yapılan çalışmalar sonucunda bu alaşımların bakır oranının belirli sınırlar içinde tutulup uygun alaşım elementleri katmak ve 1s1l işlem uygulamak suretiyle hem mekanik özelliklerinin iyileştirilmesinin hem de boyutsal kararsılık probleminin büyük ölçüde önlenmesinin mümkün olduğu görülmüştür $[15,17]$.

Son yıllarda bakır ve silisyum katkılarının özellikle yüksek oranda çinko içeren çinko-alüminyum alaşımlarının yapı ve özelliklerine etkileri üzerine yapılan çalışmalar [18, 19] üstün mekanik ve tribolojik özelliklere sahip yeni bir alaşımın (Zn-15Al-3Cu-1Si) geliştirilmesiyle sonuçlanmıştır $[20,21]$. Ancak literatürde bu alaşımın yağlı durumdaki tribolojik özellikleri hakkında herhangi bir bilimsel veri yer almamaktadır. $\mathrm{Bu}$ nedenlerden dolayı bu çalışmada $\mathrm{Zn}$ 15Al-3Cu-1Si alaşımının yağlı durumdaki tribolojik özelliklerinin sistematik olarak incelenmesi ve elde edilen bulguların ticari SAE 660 bronzundan aynı koşullarda elde edilen sonuçlarla karşılaştırılması amaçlanmıştır.

\section{DENEYSEL ÇALIŞMA (EXPERIMENTAL PROCEDURE)}

$\mathrm{Bu}$ çalışmada Zn-15Al-3Cu-1Si alaşımı kokil döküm yöntemiyle üretildi. Alaşımın üretiminde ticari saflıkta $(\% 99,7)$ alüminyum, yüksek saflıkta $(\% 99,9)$ çinko ile Al$50 \mathrm{Cu}$ ve Al-20Si master alaşımları kullanıldı. Söz konusu alaşımın üretilmesi için belirlenen miktarlardaki alaşım elementleri bir elektrikli pota fırını içerisinde ergitildi ve yaklaşık $700^{\circ} \mathrm{C}$ 'lik döküm sıcaklığından oda sıcaklığında tutulan 45 × 60 x 190 mm boyutlarındaki bir çelik kalıba (kokil) dökülerek katılaştırıldı. SAE 660 bronzu ise piyasadan temin edildi. Üretilen $\mathrm{Zn}-15 \mathrm{Al}-3 \mathrm{Cu}-1 \mathrm{Si}$ alaşımının kimyasal bileşimi atomik absorpsiyon, SAE 660 bronzunun kimyasal bileşimi ise spektral analiz yöntemiyle belirlendi. Alaşımların yapılarının incelenmesi için alınan numuneler standart metalografi yöntemleriyle hazırlandı ve farklı oranlarda nitrik asit $\left(\mathrm{HNO}_{3}\right)$ ve etanol içeren Nital ayıracı ile dağlandı. $\mathrm{Zn}-15 \mathrm{Al}-3 \mathrm{Cu}-1 \mathrm{Si}$ alaşımına ait numuneler \%3, SAE 660 bronzuna $(\mathrm{CuSn7Pb7Zn3)}$ ait numuneler ise \%30 oranında nitrik asit içeren Nital içerisinde dağlandı. Hazırlanan numuneler 1 şık ve taramalı elektron mikroskobunda (SEM) incelenerek içyap1 görüntüleri (mikrograf) elde edildi. Ayrıca, bu alaşımların içyapılarında bulunan fazların kimyasal bileşim oranları enerji dispersif spektroskopisi (EDS) yöntemiyle belirlendi. Alaşımların yoğunluklarının belirlenmesi için talaşlı yöntemle hazırlanan silindirik numunelerin hem boyutları hem de kütleleri ölçüldü. Boyutların ölçümünde $\pm 0,001 \mathrm{~mm}$ hassasiyetinde bir mikrometre, kütlelerin belirlenmesinde ise $\pm 0,01 \mathrm{mg}$ hassasiyetine sahip bir terazi kullanıldı. Kütle değerlerinin hesaplanan hacim değerlerine bölünmesiyle alaşımların yoğunlukları belirlendi. Sertlik ölçümleri Rockwell $\mathrm{F}$ yöntemi uygulanarak gerçekleştirildi ve her bir alaşımın sertliği 5 ölçümün ortalaması alınarak belirlendi.

Çekme ve basma deneylerinde ise talaşlı imalat yöntemiyle 8 x 40 TS 138 ve 10 x 10 TS 206 standartlarına uygun olarak hazırlanan numuneler kullanıldı. Üretilen numuneler $6,25 \mathrm{x}$ $10^{-3} \mathrm{~s}^{-1}$ lik ortalama deformasyon hızında deneye tabi tutuldu. Her bir alaşım için üçer adet çekme ve basma deneyi yapıldı ve sonuçların ortalaması alınarak alaşımların çekme dayanımı, kopma uzaması ve basma dayanımı değerleri belirlendi. Sürtünme ve aşınma deneyleri blok-disk esaslı bir deney düzeneğinde farklı yağ debisi, farklı basınç ve farklı kayma hızı değerlerinde 30 km'lik kayma yolu için gerçekleştirildi. $\mathrm{Bu}$ düzeneğin bir fotoğrafi Şekil 1'de verilmiştir. Söz konusu düzenek $3 \mathrm{~kW}$ gücünde bir elektrik motoru, bu motor tarafindan tahrik edilen bir mil ve buna bağlı bir aşındırma diski, numune tutucusu, yükleme kolu, hız kontrol ünitesi, yağlama sistemi ve sürtünme kuvveti ölçüm devresinden oluşmaktadır. Aşındırma diski SAE 1040 (Fe-\% 0,41 C, \% 0,90 Cu, \% 0,14Mo, \% 0,90Mn, \% 0,20Si) çeliğinden imal edildi ve 1 sıl işlemle 55 RSD-C değerine kadar sertleştirildikten sonra aşındırıcı yüzeyi taşlanarak 0,07-0,13 $\mu \mathrm{m}$ arasında yer alan bir yüzey pürüzlülüğ̈ elde edildi. Deney düzeneğindeki yağlama işlemi, numunenin bulunduğu konumdan daha yüksek bir yere yerleștirilen bir depodan ince bir hortum yardımıyla alınan SAE 20W/50 
normundaki motor yağının bir debi ayarlayıcısından geçirildikten sonra disk üzerine damlatılmasıla gerçekleştirildi. Yükleme işlemi ise, numune tutucusu ile irtibatlandırılmış olan yükleme kolunun ucuna ağırlık asmak suretiyle gerçekleştirildi. Sürtünme kuvveti numune tutucusu ile düzenekteki sabit bir mesnet arasına yerleştirilen 50 kg kapasiteli S-50 tipi bir yük hücresi yardımıyla ölçüldü. Sürtünme ve aşınma deneyleri talaşlı imalat yöntemiyle hazırlanan ve teknik resmi Şekil 2'de verilen 10 x 15 x 26,6 $\mathrm{mm}$ boyutlarındaki numuneler ile gerçekleştirildi. Deney sırasında numunelerin sıcaklığı (çalışma sıcaklığı) aşındırıcı diske temas eden yüzeylerinden $2 \mathrm{~mm}$ yukarıya açılan bir deliğe yerleştirilen bir bakır-nikel termoeleman çifti tarafından yardımıyla belirlendi ve elde edilen değerler bilgisayar ortamında $30 \mathrm{~km}$ 'lik kayma yoluna karşı gelen deney süresince kaydedildi. Sürtünme ve aşınma numuneleri hem deneylere başlamadan önce hem de deneyler tamamlandiktan sonra ultrasonik bir temizleyicide sirasiyla trikloretilen $\left(\mathrm{C}_{2} \mathrm{HCl}_{3}\right)$ ve alkol ve aseton karışımı kullanılarak temizlendi.

Temizlenen numunelerin kütleleri 0,01 mg'lık hassasiyete sahip bir terazi ile ölçüldü. Ölçülen kütle kaybı değerleri alaşımların yoğunluklarına bölünerek numunelerde aşınma ile meydana gelen hacim kayıları belirlendi. Sürtünme ve aşınma deneyleri farklı yağ debilerinde $\left(0,25-3,0 \mathrm{~cm}^{3} \mathrm{~h}^{-1}\right)$, kayma hızlarında $\left(0,5-3,0 \mathrm{~ms}^{-1}\right)$ ve basınçlarda $(1-8 \mathrm{MPa})$ gerçekleştirildi.

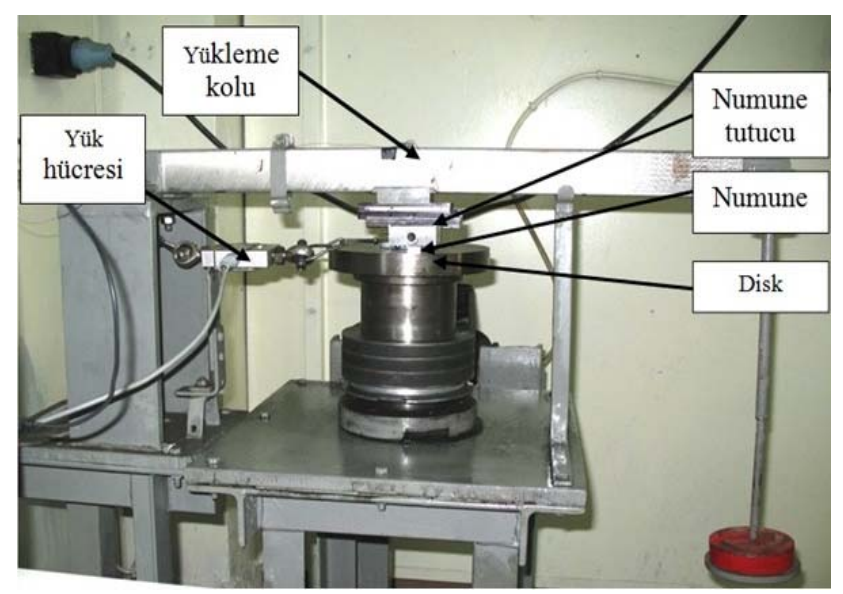

Şekil 1. Aşınma deney makinesinin fotoğrafi

(A photograph of the wear test machine)

\section{SONUÇLAR VE TARTIŞMALAR (RESULTS AND DISCUSSIONS)}

İncelenen Zn-15Al-3Cu-1Si alaşımı ve SAE 660 bronzunun kimyasal bileşimleri Tablo 1'de, içyapılarının SEM görüntüleri Şekil 3'de verilmiştir. Zn-15Al-3Cu-1Si alaşımının içyapısının $\beta$ dendritleri ile bunları çevreleyen $\beta$ $+\eta$ ötektik karışımı, $\beta$ fazının dönüşüm ürünleri olan $\alpha$ ve $\eta$ fazları ile $\varepsilon\left(\mathrm{CuZn}_{4}\right)$ ve silisyum parçacıklarından oluştuğu gözlendi (Şekil 3a). SAE 660 bronzunun içyapısının ise bakırca zengin $\alpha$ dendritleri ile bunları çevreleyen ötektoid $\alpha$ ve $\delta$ fazlarını içerdiği görüldü (Şekil 3b).
Tablo 1. İncelenen alaşımların kimyasal bileşimleri (Chemical compositions of the experimental alloys)

\begin{tabular}{lllllll}
\hline \multirow{2}{*}{ Alaşım } & \multicolumn{6}{c}{ Kimyasal bileşim oranı (\% ağırlık) } \\
\cline { 2 - 7 } & $\mathrm{Zn}$ & $\mathrm{Al}$ & $\mathrm{Cu}$ & $\mathrm{Si}$ & $\mathrm{Sn}$ & $\mathrm{Pb}$ \\
\hline Zn-15Al-3Cu- & 81,3 & 14,9 & 2,9 & 0,9 & - & - \\
$\begin{array}{l}\text { 1 Si } \\
\text { SAE 660 } \\
\text { bronzu }\end{array}$ & 4,0 & - & 82,8 & - & 6,9 & 6,3 \\
\hline
\end{tabular}
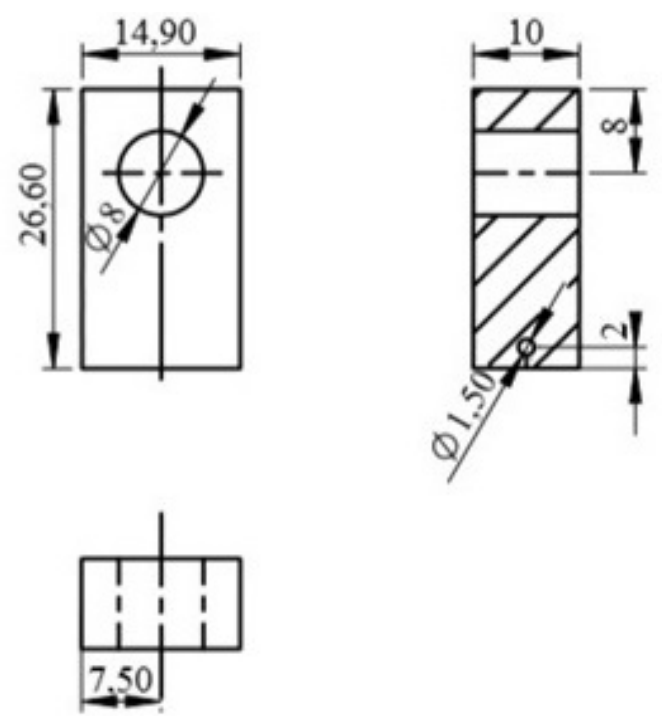

Şekil 2. Aşınma deney numunesinin teknik resmi (Technical drawing of the wear sample)

Zn-15Al-3Cu-1Si alaşımının dendritler arası bölgelerinde $\varepsilon$ fazının oluşması bakırın bu alaşımlardaki çözünme durumuna göre açıklanabilir. Yapılan EDS analizleri bakırın bu alaşımların matrisini oluşturan $\beta$ fazı içerisindeki en yüksek çözünme oranının $\% 3$ dolayında olduğunu göstermiştir. Bu duruma göre \%3 ve daha yüksek oranlarda bakır içeren alaşımlarda gözlenen $\varepsilon$ fazının $\beta$ fazı içerisinde çözünemeyen fazlalık bakırın çinko ile reaksiyona girmesi sonucunda oluştuğu söylenebilir [20, 22]. Silisyum parçacıklarının yapı içerisinde belirli bölgelerde kümelendikleri yani homojen bir dağılım sergilemedikleri gözlendi. Yapılan metalografik incelemeler ve EDS analizleri söz konusu parçacıkların birincil (primer) silisyum parçacıkları olduklarını göstermiştir. Bu parçacıkların yapı içerisinde kümeleşmeleri yoğunluk farkına dayandırılarak açıklanabilir. Şöyle ki, yoğunluğu düşük olan bu parçacıklar sıvı metal içersinde yüzeye doğru hareket ederlerken birbirlerine rastgele çarparak veya temas ederek bir arada toplanırlar. Sıvı içerisinde meydana gelen bu durum silisyum parçacıklarının içyapıda kümeleşmesine yol açmış olabilir [23]. Zn-15Al-3Cu-(0-3)Si alaşımı ve SAE 660 bronzunun yoğunluk, sertlik, çekme dayanımı, kopma uzaması ve basma dayanımı değerleri Tablo 2'de verilmiştir. Zn-15Al3Cu-1Si alaşımı ve SAE 660 bronzuna ait numunelerden elde edilen sürtünme katsayısı, çalışma sıcaklığı ve hacim kaybı değerlerinin yağ debisi, basınç ve kayma hızına göre değişimlerini gösteren eğriler sırasıyla Şekil 4 ve 5'de verilmiştir. 
Tablo 2. Zn-15Al-3Cu-1Si alaşımı veSAE 660 bronzunun yoğunluk, sertlik, çekme dayanımı, kopma uzaması ve basma dayanımı değerleri

(The values of density, hardness, tensile strength, elongation to fracture, and compressive strength of $\mathrm{Zn}-15 \mathrm{Al}-3 \mathrm{Cu}-1 \mathrm{Si}$ alloy and SAE 660 bronze)

\begin{tabular}{llllll}
\hline Alaşım & $\begin{array}{l}\text { Yoğunluk } \\
\left(\mathrm{kg} / \mathrm{m}^{3}\right)\end{array}$ & $\begin{array}{l}\text { Sertlik } \\
(\mathrm{RSD}-\mathrm{F})\end{array}$ & $\begin{array}{l}\text { Çekme } \\
\text { dayanımı } \\
(\mathrm{MPa})\end{array}$ & $\begin{array}{l}\text { Kopma } \\
\text { uzaması (\%) }\end{array}$ & $\begin{array}{l}\text { Basma } \\
\text { dayanımı } \\
(\mathrm{MPa})\end{array}$ \\
\hline $\mathrm{Zn}-15 \mathrm{Al}-3 \mathrm{Cu}-1 \mathrm{Si}$ & 5696,7 & 92 & 314 & 1,9 & 785 \\
SAE 660 bronzu & 8901,1 & 83 & 295 & 15,0 & 1080 \\
\hline
\end{tabular}

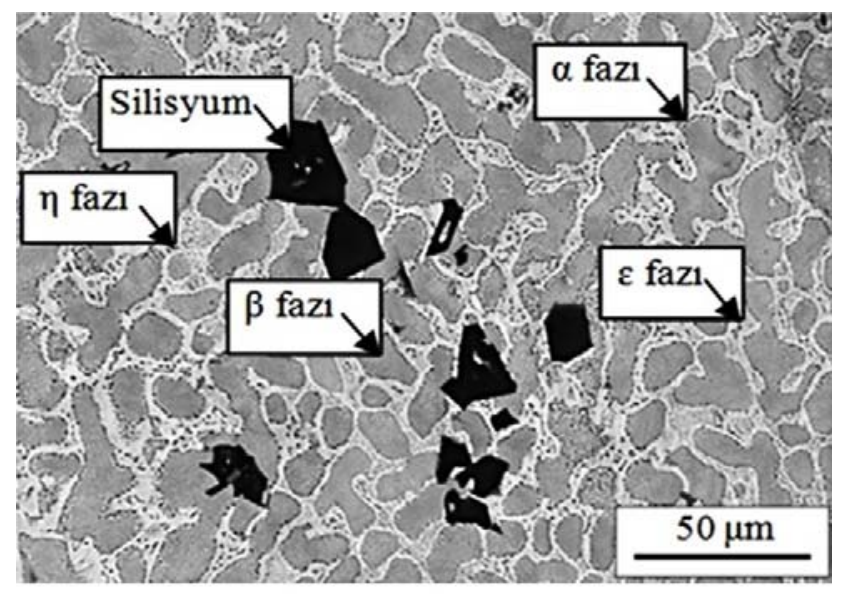

(a)

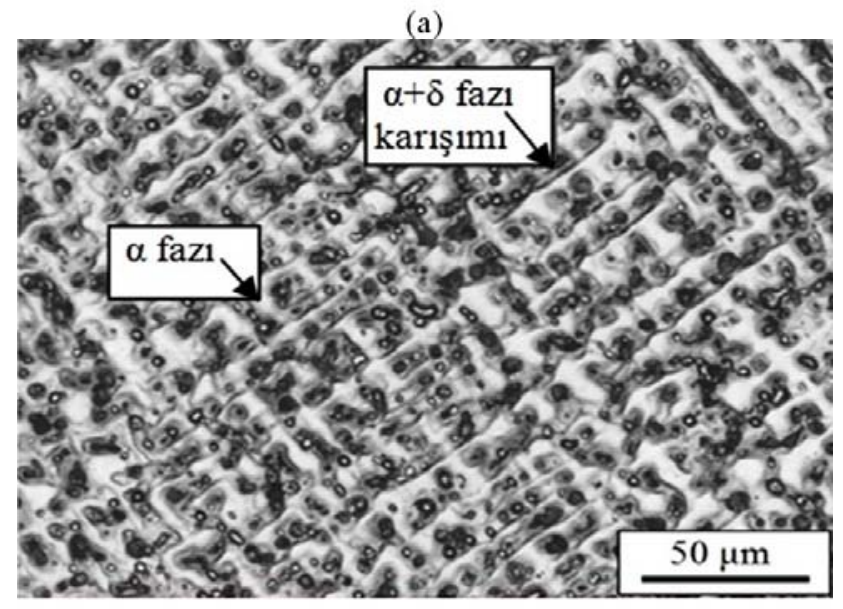

(b)

Şekil 3. a) Zn-15Al-3Cu-1Si alaşımı b) SAE 660

bronzunun içyapılarının SEM görüntüleri (SEM micrographs of the microstructures of a) Zn-15Al-3Cu-1Si alloy b) SAE 660 bronze)

$\mathrm{Bu}$ eğriler söz konusu alaşımların sürtünme katsayısı, çalışma sıcaklığı ve hacim kaybı değerlerinin artan yağ debisi ile azaldığını göstermektedir (Şekil 4a ve 5a). Söz konusu değerlerde meydana gelen azalmalar artan yağ debisi ile yağ filmi kalınlığının artması ve dolayısıyla metal-metal temasının azalmasından kaynaklanmış olabilir. Bu gözlemin literatürde yer alan bulgularla uyum içerisinde olduğu görülmüştür [24]. Sabit yağ debisi $\left(1 \mathrm{~cm}^{3} / \mathrm{saat}\right)$ ve kayma hızında $(2 \mathrm{~m} / \mathrm{s})$ aşınma deneyine tabi tutulan alaşımların sürtünme katsayısının artan basınç ile azaldığı, sıcaklık ve hacim kaybı değerlerinin ise sürekli arttığı görüldü (Şekil 4b ve $5 \mathrm{~b}$ ). Bu durum belirtilen koşullardaki çalışma sırasında hidrodinamik yağlamanın gerçekleştiğini göstermektedir.

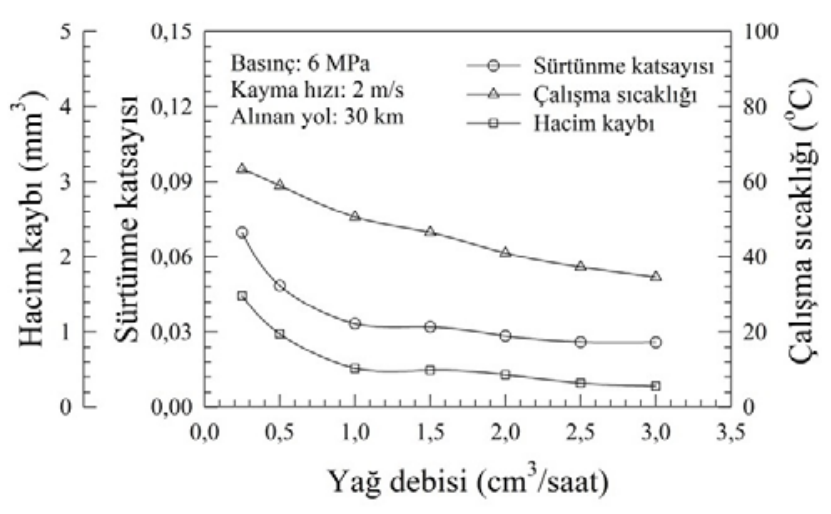

(a)

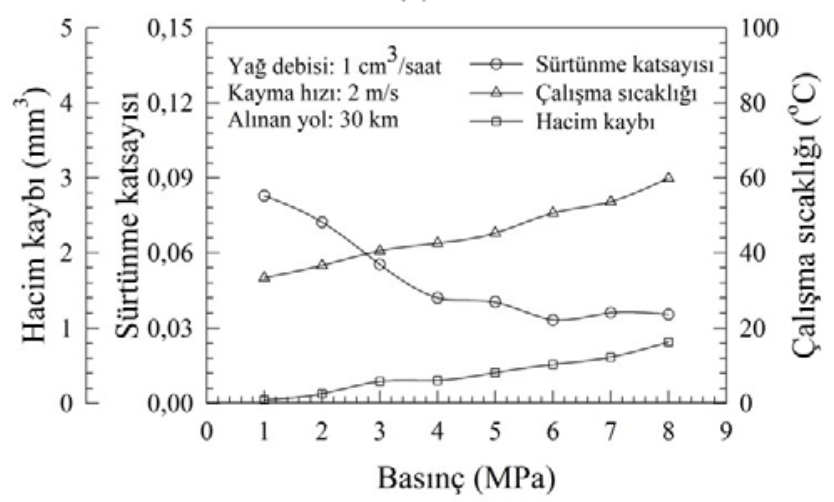

(b)

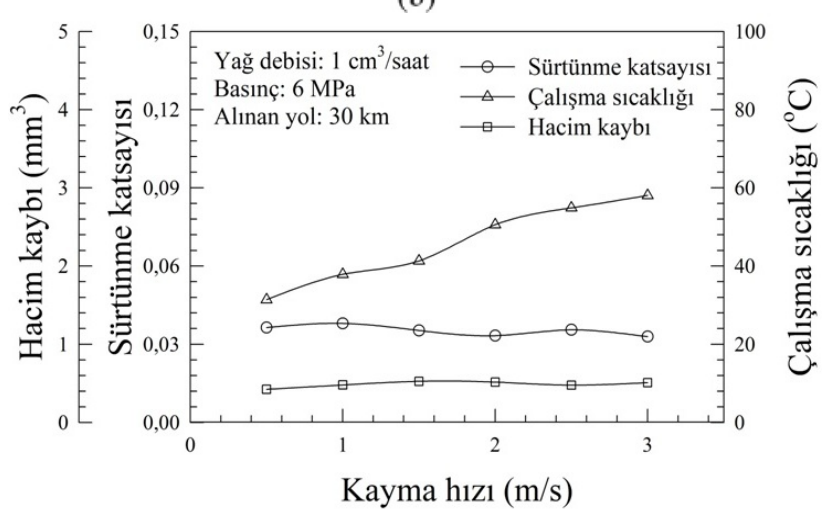

(c)

Şekil 4. Zn-15Al-3Cu-1Si alaşımının sürtünme katsayıs1, sıcaklık ve hacim kaybı değerlerinin (a) yağ debisine (b) basınca (c) kayma hızına göre değişimlerini gösteren eğriler (The curves showing the changes in the friction coefficient, working temperature and wear volume, of $\mathrm{Zn}-15 \mathrm{Al}-3 \mathrm{Cu}-1 \mathrm{Si}$ alloy as a function of (a) oil flow rate (b) pressure (c) sliding speed) 


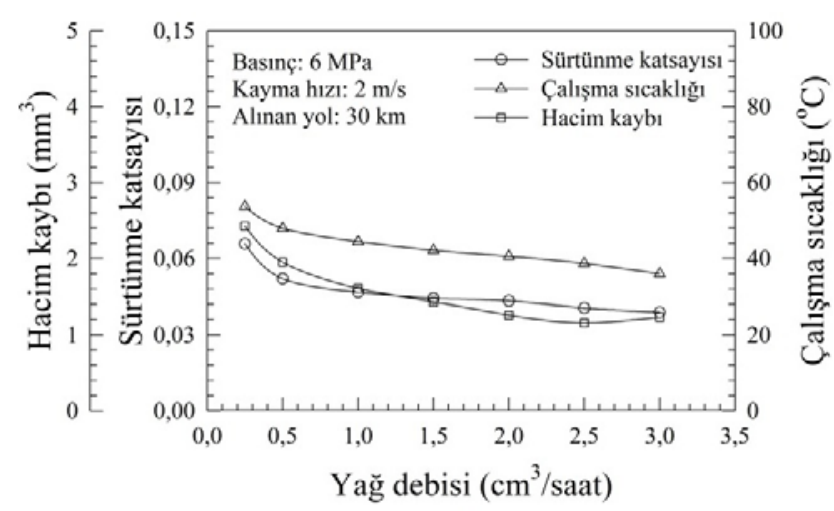

(a)

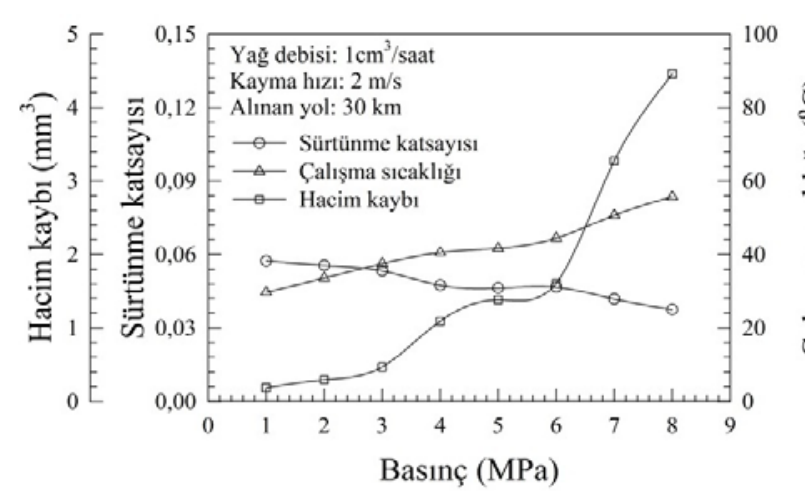

(b)

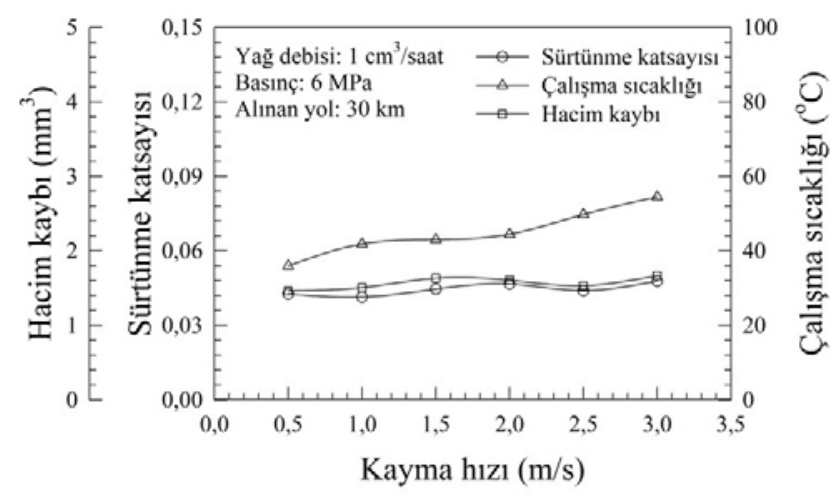

(c)

Şekil 5. SAE 660 bronzunun sürtünme katsayısı, sıcaklık ve hacim kaybı değerlerinin a) yağ debisine b) basınca ve c) kayma hızına göre değişimlerini gösteren eğriler

(The curves showing the changes in friction coefficient, working temperature and wear volume of SAE 660 bronze as a function of (a) oil flow rate (b) pressure (c) sliding speed)

Nitekim yağlı sistemlerin sürtünme katsayısının yalnız hidrodinamik yağlama devresinde artan basınçla azaldığı bilinmektedir [24, 25]. Basınç arttıkça yüzeyler arasındaki yăg filmi kalınlığının azaldığı bilinmektedir [26, 27]. Yağ filmi kalınlığının azalması yağ molekülleri arasındaki sürtünmenin azalmasına ve dolayısıyla sürtünme katsayısının düşmesine yol açmış olabilir. Sıcaklık ve hacim kaybı değerlerinin sürekli artması ise özellikle rodaj döneminde meydana gelen metal-metal temasinın artan basınç ile artması nedeniyle sürtünme kuvvetinin ve sürtünme 1sısının yükselmesinden kaynaklanmış olabilir. Sabit yağ debisi ( $1 \mathrm{~cm}^{3} /$ saat) ve sabit basınç (6 MPa) altında yapılan aşınma deneylerinde kayma hızı arttıkça alaşımların sıcaklığının sürekli arttığı, sürtünme katsayısı ve hacim kaybı değerlerinin ise fazla değişmediği gözlendi (Şekil 4c ve 5c). Artan kayma hızıyla sıcaklığın artması yağa etki eden merkezkaç kuvveti ile yağda meydana gelen çalkalanmaya dayandırılarak açıklanabilir. Şöyle ki, kayma hızı arttıkça disk ve numune yüzeylerindeki yağa etki den merkezkaç kuvveti artar ve yüzeyler arasındaki yağda daha fazla çalkalanma meydana gelir. Yağa etki eden merkezkaç kuvveti ve çalkalanmanın artması daha fazla yağın savrularak sistemden uzaklaşmasına ve yağ içerisinde daha fazla sürtünmenin meydana gelmesine neden olur. Hem yağ miktarının azalması hem de yağ içerisindeki sürtünmenin artması numune sıcaklığının artmasına yol açabilir. Sicaklığın artması yağ viskozitesinin azalmasına neden olur. Yağ viskozitesinin azalması da yağın iç sürtünmesinde meydana gelen artışı dengeleyerek sürtünme katsayısının fazla değişmemesine yol açmış olabilir.

Alaşımlarda aşınma ile meydana gelen hacim kaybının kayma hızından fazla etkilenmemesi ise, aşınma hızının en yüksek olduğu rodaj döneminin süre olarak artan kayma hızıyla azalmasına rağmen, yol olarak değişmemesinden kaynaklanmış olabilir. Zn-15Al-3Cu-1Si alaşımının SAE 660 bronzuna göre tüm deney koşullarında çok daha düşük hacim kaybı veya yüksek aşınma direnci sergilediği görüldü (Şekil 6). Bu durum söz konusu alaşımının içyapısı, sertlik ve mukavemet değerleri ile aşınma yüzeylerinde oluşan oksit filmlerine dayandırılarak açıklanabilir. Şöyle ki, çinko esaslı alaşımların içyapısında bulunan alüminyum ve bakırca zengin fazlar ile silisyum parçacıkları yük taşıma görevi yaparken, nispeten yumuşak olan $\eta$ fazı ile aşınma sırasında oluşan çinko oksit tabakası kaymayı kolaylaştırmaktadır [4, 28]. Ayrıca, bu alaşımların yumuşak olan matrisinin aşınma parçacıklarını yutma veya içine alma özelliğine sahip olduğu bilinmektedir [27, 29]. Öte yandan çinko esaslı alaşımların sertlik ve mukavemet değerlerinin, SAE 660 bronzunun söz konusu değerlerinden daha yüksek olduğu görülmektedir (Tablo 2). $\mathrm{Bu}$ verilere dayanarak $\mathrm{Zn}-15 \mathrm{Al}-3 \mathrm{Cu}-1 \mathrm{Si}$ alaşımının SAE 660 bronzuna göre daha yüksek aşınma direnci sergilemesinin, içyapısının tribolojik uygulamalar için uygun olması ve yüzeylerinde yük taşıma kapasitesini artırıcı alüminyum oksit (alümina) ve kaymayı kolaylaştırıcı çinko oksit filmlerinin oluşmasının yanı sıra daha yüksek sertlik ve mukavemet değerlerine sahip olmasından kaynaklandığı söylenebilir. Deneylere başlamadan önce aşınma numunelerinin yüzeylerinden elde edilen SEM görüntüleri Şekil 7'de verilmiştir. Bu görüntüler her iki alaşıma ait numunelerin yüzeylerinde farklı kalem izlerinin yer aldığını göstermektedir. Şöyle ki, Zn-15Al-3Cu-1Si alaşıma ait numunenin yüzeyinde sıvanma belirtileri baskın bir görünüm sergilerken, SAE 660 bronzuna ait numunenin yüzeyinde çizikler ön plana çıkmaktadır. Deney numunelerinin aşınma yüzeylerinden farklı yă̆ debisi, basınç ve kayma hızlarında yapılan deneyler sonucunda elde edilen SEM görüntüleri sırasıyla Şekil 8- 13'de verilmiştir. 


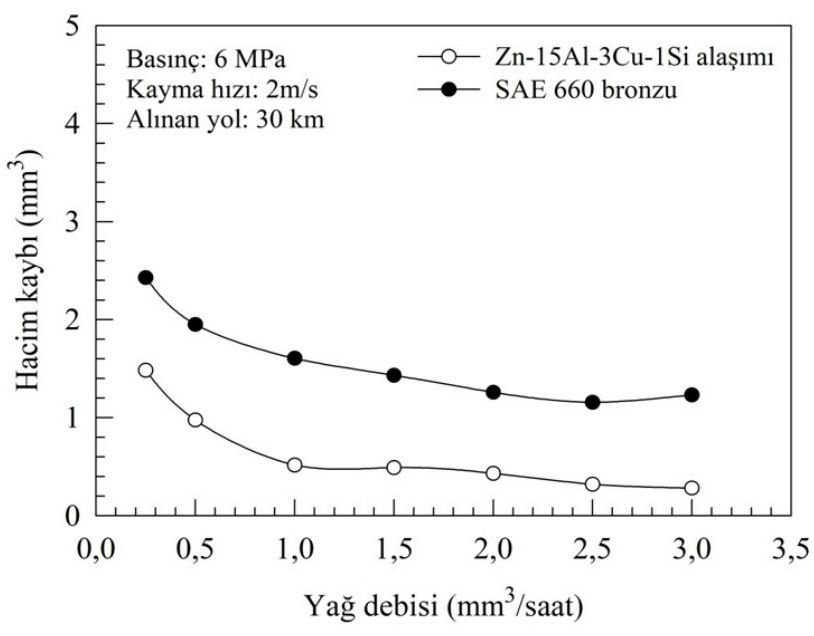

(a)

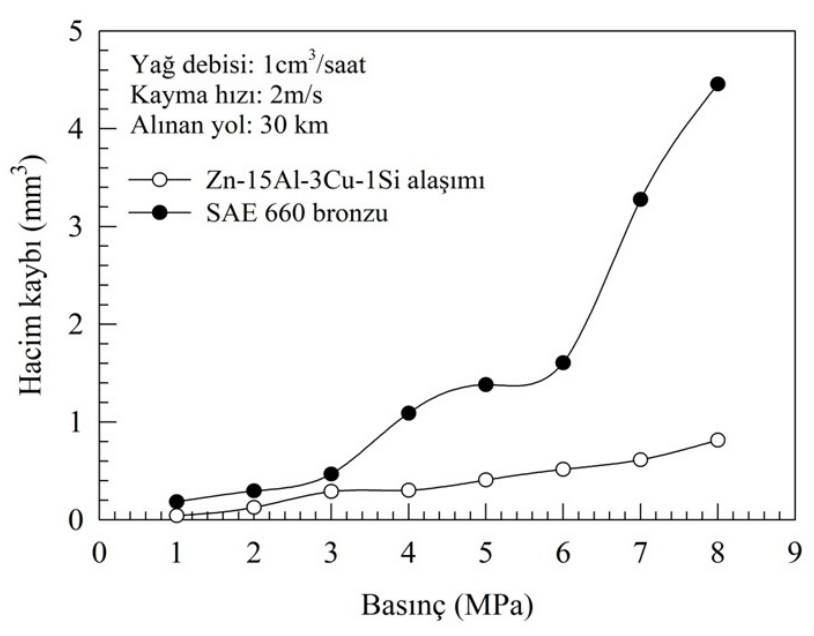

(b)

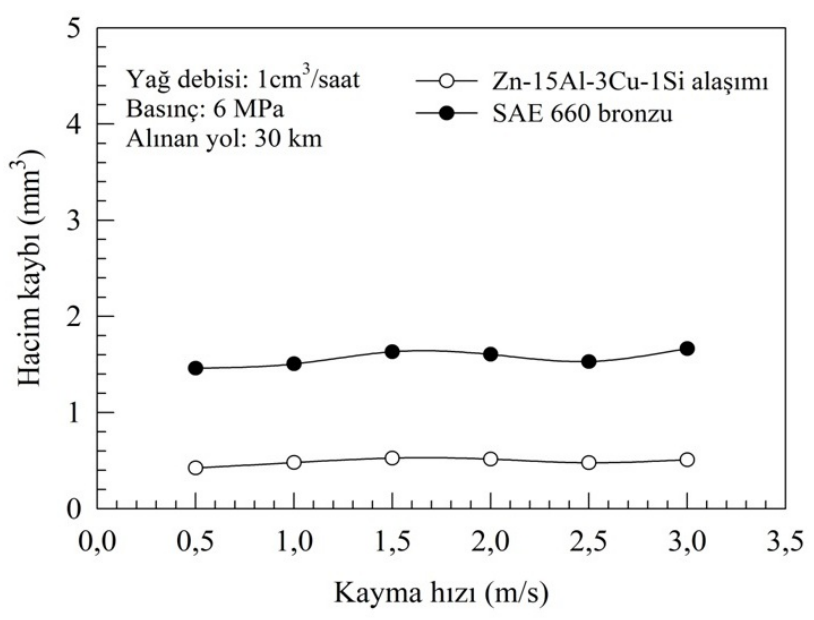

(c)

Şekil 6. Zn-15Al-3Cu-1Si alaşımı ve SAE 660 bronzunun hacim kaybı değerlerinin a) yağ debisine b) basınca ve c) kayma hızına göre değişimlerini gösteren eğriler

(The curves showing the changes in wear volume of the $\mathrm{Zn}-15 \mathrm{Al}-3 \mathrm{Cu}-1 \mathrm{Si}$ alloy and SAE 660 bronze as a function of (a) oil flow rate (b) pressure, and (c) sliding speed)

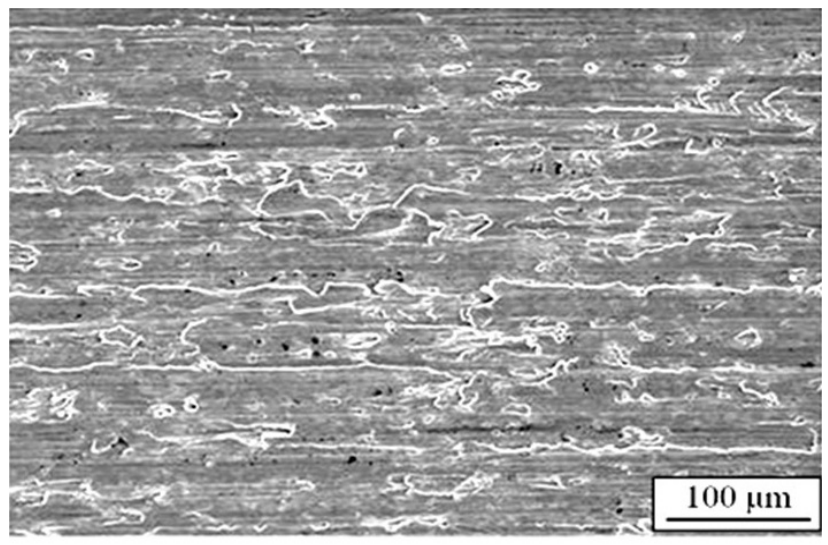

(a)

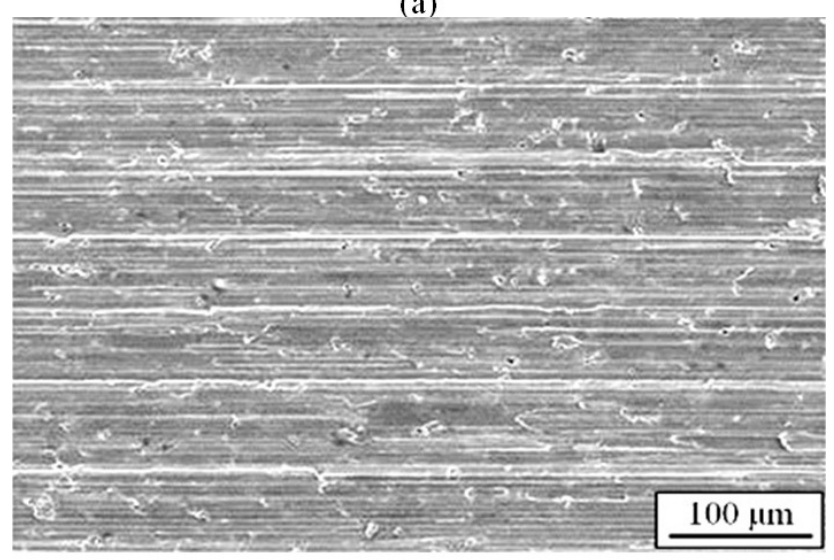

(b)

Şekil 7. a) Zn-15Al-3Cu-1Si alaşımı ve b) SAE 660 bronzuna ait aşınma numunelerinin yüzeylerinden deney öncesi elde edilen SEM görüntüleri

(SEM micrographs obtained from the wear surfaces of (a) $\mathrm{Zn}-15 \mathrm{Al}-3 \mathrm{Cu}-$ 1Si alloy and (b) SAE 660 bronze before the tests)

Bu görüntüler söz konusu alaşımlara ait numunelerin aşınma yüzeylerindeki sıvanmış bölge alanının artan yă̆ debisi ile azalıp artan basınçla arttığını göstermektedir, Şekil 8, 9, 11 ve 12. Ancak kayma hızının bu alaşımların aşınma yüzeyi üzerinde belirgin bir etkiye sahip olmadığı görüldü (Şekil 10 ve 13). $\mathrm{Bu}$ gözlemler numunelerin özellikle rodaj dönemindeki aşınma davranışlarına göre açıklanabilir.

Numune yüzeyindeki sıvanmanın daha çok rodaj döneminde meydana geldiği bilinmektedir [30]. Yağ debisinin artması yağ filmi oluşumu ve kalınlaşmasını hızlandırarak yüzeyler arasındaki metal-metal temasinın azalmasina neden olmaktadır. Metal-metal temasının azalması aşınmanın azalmasına, aşınmanın azalması da sıvanan malzeme miktarının azalmasına yol açar. Bu nedenle yağ debisi arttıkça sıvanan yüzey alanı azalır. Sıvanan yüzey alanın artan basınç ile artması, rodaj döneminde gittikçe artan oranda aşınmanın meydana gelmesi ve aşınan malzemenin daha geniş yüzeye yayılmasının bir sonucu olabilir. Numunelerin aşınma yüzeylerinin kayma hızından fazla etkilenmemesi ise, rodaj döneminin süre olarak artan kayma hızı ile azalmasına rağmen, kayma yolu olarak fazla değişmemesinden kaynaklanmış olabilir. 


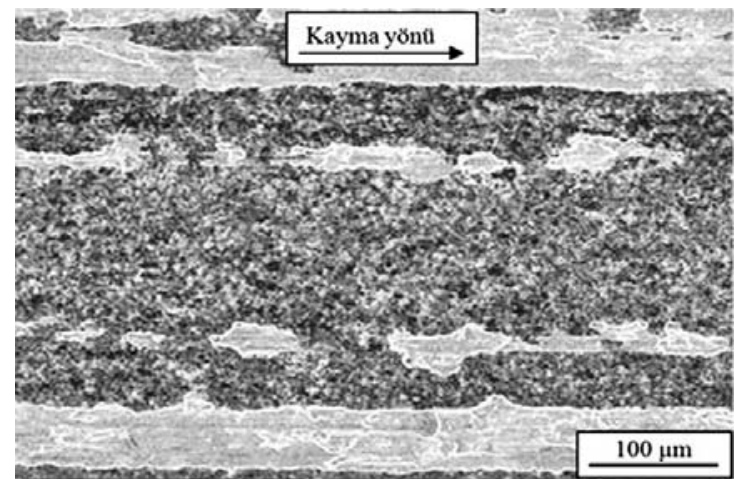

(a)

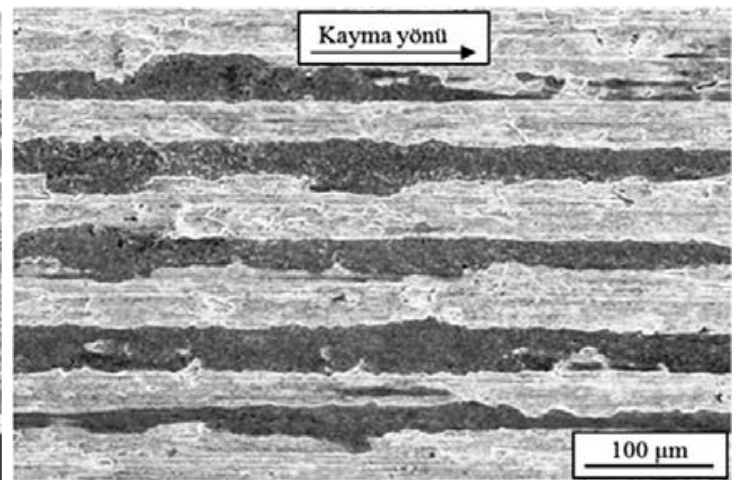

(b)

Şekil 8. $6 \mathrm{MPa}$ 'lık basınç ve $2 \mathrm{~m} / \mathrm{s}^{\prime}$ lik kayma hızında a) $0,25 \mathrm{~cm}^{3} /$ saat ve b) $3 \mathrm{~cm}^{3} / \mathrm{saat}^{\prime} l i k$ yağ debisinde deneye tabi tutulan $\mathrm{Zn}-15 \mathrm{Al}-3 \mathrm{Cu}-1 \mathrm{Si}$ alaşımına ait aşınma numunelerinin yüzeylerinden elde edilen SEM görüntüleri

(SEM micrographs obtained from the wear samples of $\mathrm{Zn}-15 \mathrm{Al}-3 \mathrm{Cu}-1 \mathrm{Si}$ alloy tested at a constant pressure of $6 \mathrm{MPa}$, a sliding speed of $2 \mathrm{~ms}^{-1}$ and two different oil flow rates of (a) $0.25 \mathrm{~cm}^{3} \mathrm{~h}^{-1}$ and (b) $3 \mathrm{~cm}^{3} \mathrm{~h}^{-1}$ )

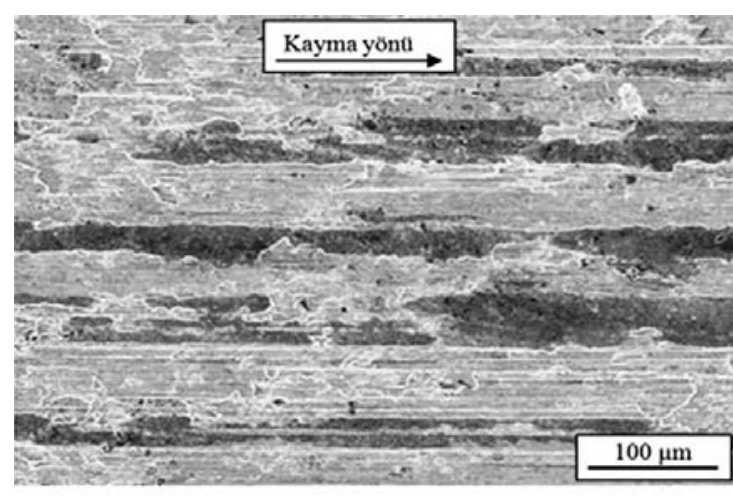

(a)

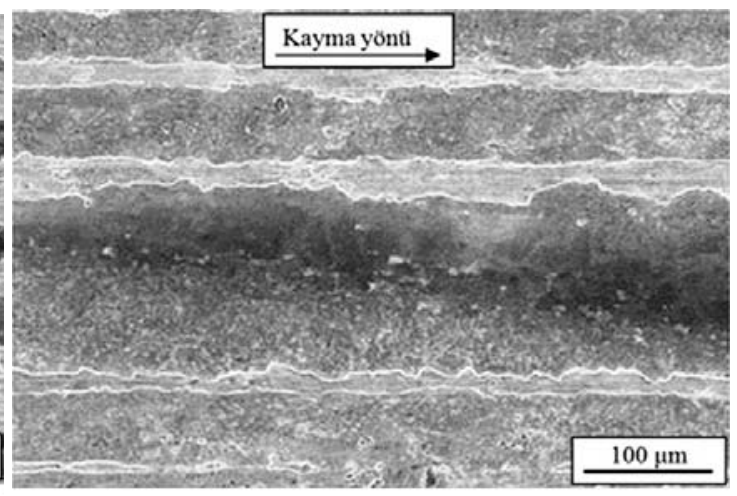

(b)

Şekil 9. Sabit yağ debisi ( $\left.1 \mathrm{~cm}^{3} / \mathrm{saat}\right)$ ve sabit kayma hızı $(2 \mathrm{~m} / \mathrm{s})$ koşullarında a) $1 \mathrm{MPa}$ ve b) $8 \mathrm{MPa}$ değerindeki basınçlar altında deneye tabi tutulan $\mathrm{Zn}-15 \mathrm{Al}-3 \mathrm{Cu}-1 \mathrm{Si}$ alaşımına ait numunelerin aşınma yüzeylerinden elde edilen SEM görüntüleri (SEM micrographs obtained from the wear samples of $\mathrm{Zn}-15 \mathrm{Al}-3 \mathrm{Cu}-1 \mathrm{Si}$ alloy tested ata constant oil flow rate $\left(1 \mathrm{~cm}^{3} \mathrm{~h}^{-1}\right)$ a constant sliding speed $\left(2 \mathrm{~ms}^{-1}\right)$ and two different contact pressures of (a) $1 \mathrm{MPa}$ and (b) $8 \mathrm{MPa}$ )

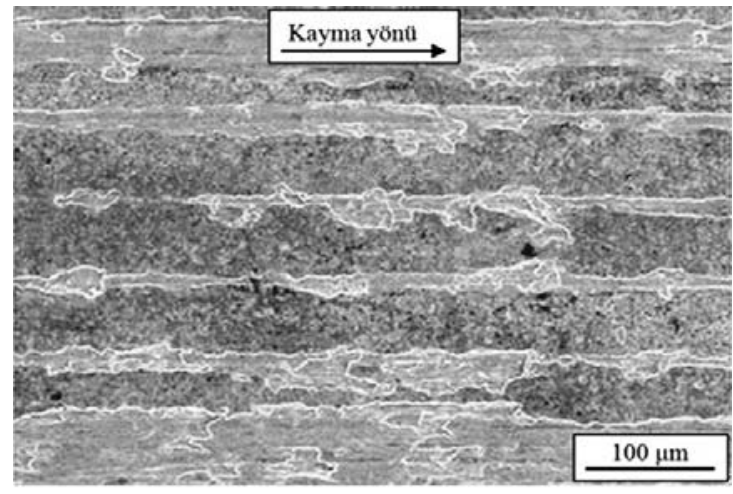

(a)

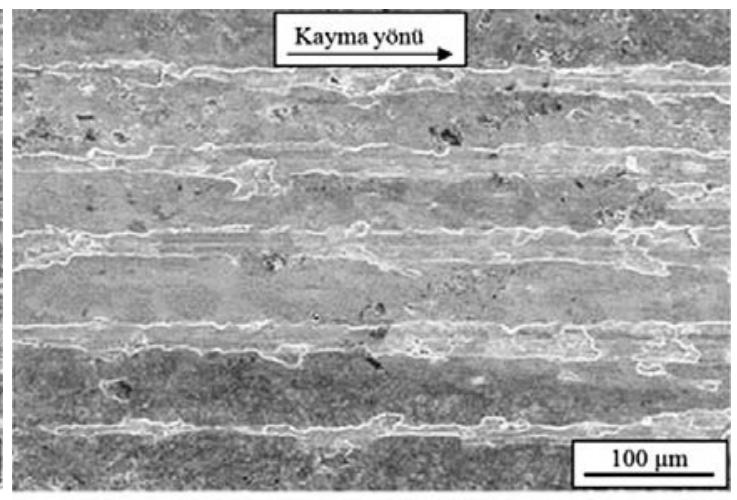

(b)

Şekil 10. $1 \mathrm{~cm}^{3} /$ saat'lik yağ debisi ve $6 \mathrm{MPa}$ 'lık basınç koşullarında a) $10,5 \mathrm{~m} / \mathrm{s}$ ve b) $3 \mathrm{~m} / \mathrm{s}$ 'lik kayma hızlarında aşınma deneyine tabi tutulan $\mathrm{Zn}-15 \mathrm{Al}-3 \mathrm{Cu}-1 \mathrm{Si}$ alaşımına ait numunelerin aşınma yüzeylerinden elde edilen SEM görüntüleri (SEM micrographs obtained from the wear samples of Zn-15Al-3Cu-1Si alloy tested at an oil flow rate of $1 \mathrm{~cm}^{3} \mathrm{~h}^{-1}$, a pressure of $6 \mathrm{MPa}$ and two different sliding speeds of (a) $0.5 \mathrm{~ms}^{-1}$ and (b) $3 \mathrm{~ms}^{-1}$ ) 


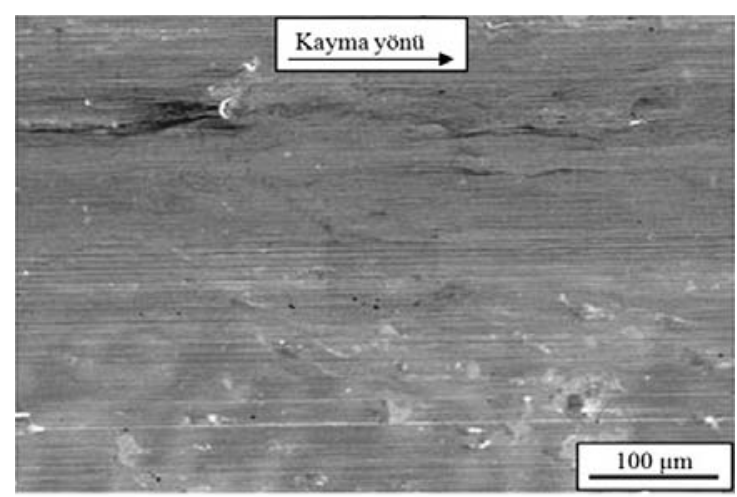

(a)

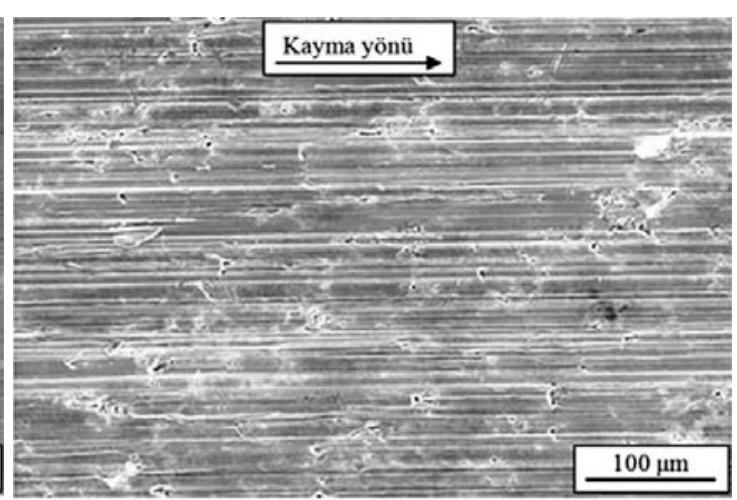

(b)

Şekil 11. $6 \mathrm{MPa}$ 'lık basınç ve $2 \mathrm{~m} / \mathrm{s}^{\prime}$ lik kayma hızında a) $0,25 \mathrm{~cm}^{3} / \mathrm{saat}$ ve b) $3 \mathrm{~cm}^{3} / \mathrm{saat}^{\prime}$ lik yağ debisi değerlerinde deneye tabi tutulan SAE 660 bronzuna ait aşınma numunelerinin yüzeylerinden elde edilen SEM görüntüleri

(SEM micrographs obtained from the wear samples of SAE 660 bronze tested at a pressure of $6 \mathrm{MPa}$, a sliding speed of $2 \mathrm{~ms}^{-1}$ ans two different oil flow rates of (a) $0.25 \mathrm{~cm}^{3} \mathrm{~h}^{-1}$ and (b) $3 \mathrm{~cm}^{3} \mathrm{~h}^{-1}$ )

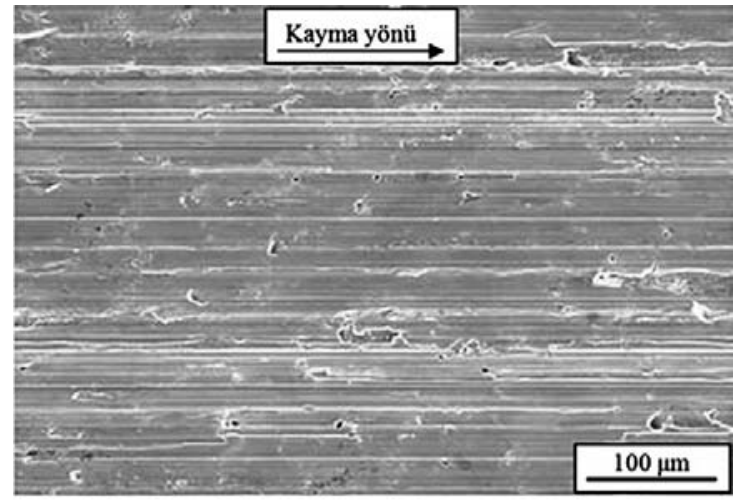

(a)

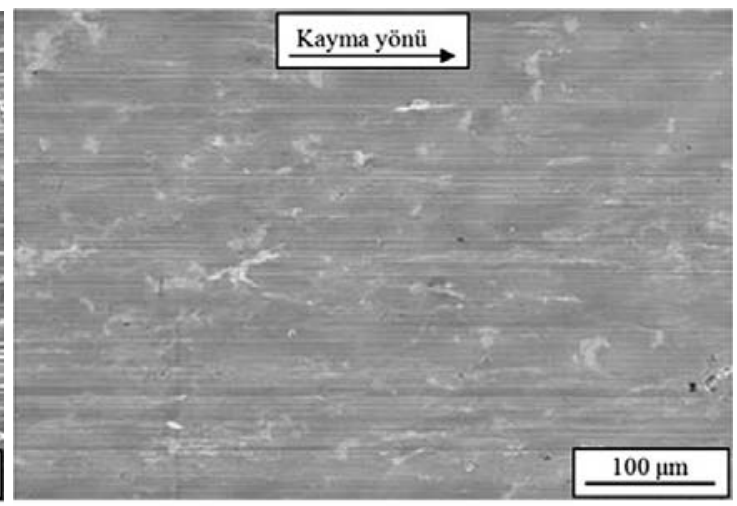

(b)

Şekil 12. Sabit yağ debisi $\left(1 \mathrm{~cm}^{3} / \mathrm{saat}\right)$ ve sabit kayma hızı $(2 \mathrm{~m} / \mathrm{s})$ koşullarında a) $1 \mathrm{MPa}$ ve b) $8 \mathrm{MPa}$ değerindeki basınçlar altında deneye tabi tutulan SAE 660 bronzuna ait aşınma numunelerinin yüzeylerinden elde edilen SEM görüntüleri (SEM micrographs obtained from the wear samples of SAE 660 bronze tested at a constant oil flow rate $\left(1 \mathrm{~cm}^{3} \mathrm{~h}^{-1}\right)$, a constant sliding speed $\left(2 \mathrm{~ms}^{-1}\right)$ and two different contact pressures of (a) $1 \mathrm{MPa}$ and (b) $8 \mathrm{MPa}$ )

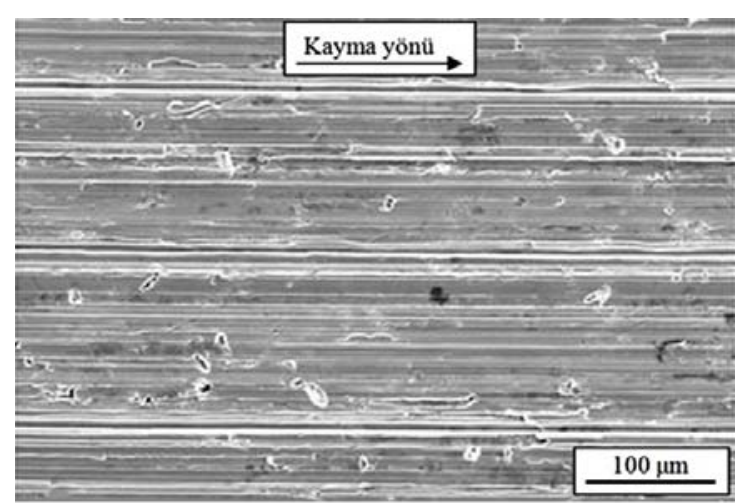

(a)

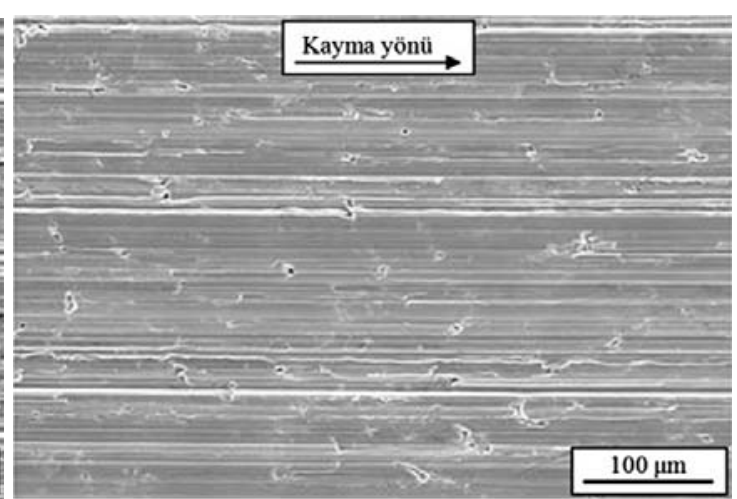

(b)

Şekil 13. $1 \mathrm{~cm}^{3} /$ saat'lik yağ debisi ve $6 \mathrm{MPa}$ 'lık basınç koşullarında a) $20,5 \mathrm{~m} / \mathrm{s}$ ve b) $3 \mathrm{~m} / \mathrm{s}$ 'lik kayma hızlarında aşınma deneyine tabi tutulan SAE 660 bronzuna ait aşınma numunelerinin yüzeylerinden elde edilen SEM görüntüleri

(SEM micrographs obtained from the wear samples of SAE 660 bronze tested at anoil flow rate of $1 \mathrm{~cm}^{3} \mathrm{~h}^{-1}$, a pressure of $6 \mathrm{MPa}$ and two different sliding speeds of (a) $0.5 \mathrm{~ms}^{-1}$ and (b) $3 \mathrm{~ms}^{-1}$ ) 


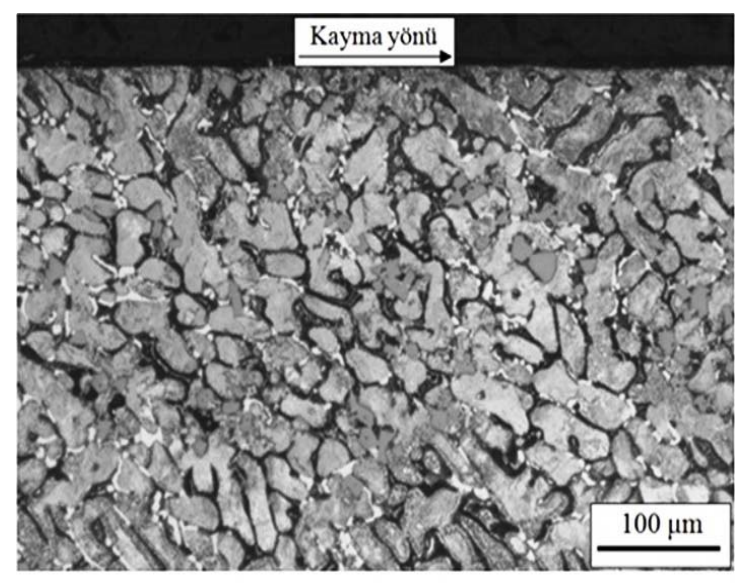

(a)

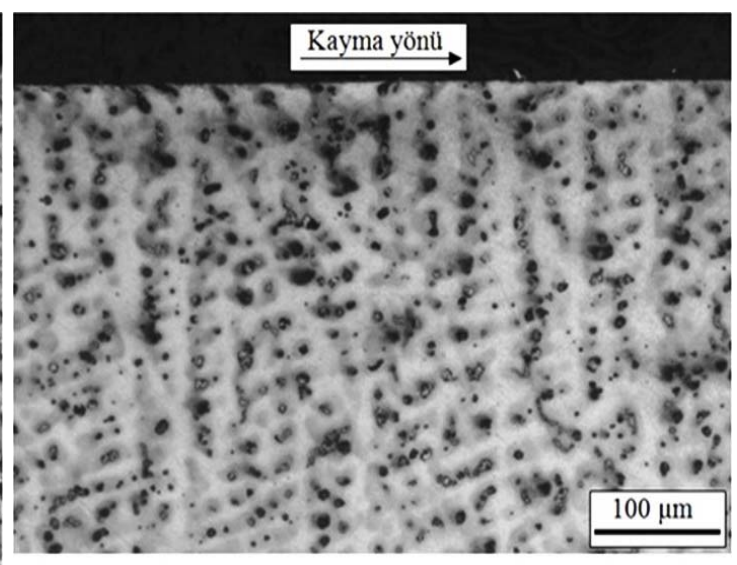

(b)

Şekil 14. $8 \mathrm{MPa}$ 'lık basınç ve $2 \mathrm{~m} / \mathrm{s}^{\prime}$ lik kayma hızında $30 \mathrm{~km}$ tutarındaki yol alınıncaya kadar aşınma deneyine tabi tutulan a) Zn-15Al-3Cu alaşımı ve b) SAE 660 bronzuna ait numunelerin kayma doğrultusuna paralel kesitlerininSEM görüntüleri (SEM micrographs of the subsurface microstructure of the wear samples of (a) Zn-15Al-3Cu alloy and (b) SAE 660 bronze tested at a contact pressure of $8 \mathrm{MPa}$ and a sliding speed of $2 \mathrm{~ms}^{-1}$ for a sliding distance of $3 \mathrm{~km}$ )

$\mathrm{Zn}-15 \mathrm{Al}-3 \mathrm{Cu}$ alaşımı ve SAE 660 bronzunun $8 \mathrm{MPa}$ lık basınç ve $2 \mathrm{~m} / \mathrm{s}^{\prime}$ lik kayma hızında aşınma deneyine tabi tutulan numunelerine ait kayma doğrultusuna paralel kesit görüntüleri Şekil 14'de ve bu kesitlerdeki mikrosertlik değerinin derinliğe göre değişimini gösteren eğriler ise Şekil 15 'de verilmiştir.

Bu görüntü ve eğirler incelenen alaşımların yüzey altında önemli bir yapısal değişimin olmadığını göstermektedir. Bu durum deney sırasında oluşan sıcaklık ve basınç değerlerinin malzemenin yapısında değişikliğe yol açacak seviyelere ulaşmamasından kaynaklanmış olabilir.

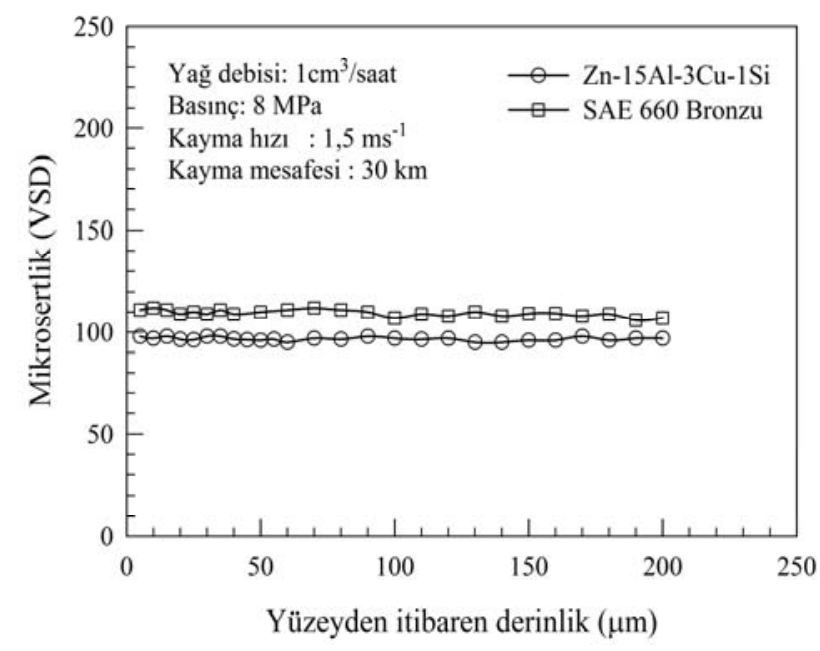

Şekil 15. Zn-15Al-3Cu-1Si alaşımı ve SAE 660 bronzuna ait aşınma numunelerinin kayma doğrultusuna paralel kesitlerinden elde edilen mikrosertlik değerlerinin derinliğe göre değişimini gösteren eğriler (The curves showing the changes in the microhardness of the wear samples of $\mathrm{Zn}-15 \mathrm{Al}-3 \mathrm{Cu}-1 \mathrm{Si}$ alloy and SAE 660 bronze as a function of depth from the wear surface)

\section{SONUÇLAR (CONCLUSIONS)}

Zn-15Al-3Cu-1 Si alaşımının içyapısı $\beta$, ötektik $\beta+\eta$, ötektoid $\alpha+\eta$ ve $\varepsilon$ fazlarının yanı sıra birincil silisyum parçacıklarından oluşmaktadır. Zn-15Al-3Cu-1Si alaşımı SAE 660 bronzundan daha düşük yoğunluk, ancak daha yüksek sertlik ve çekme dayanımı sergilemektedir. Yăg debisi arttıkça $\mathrm{Zn}-15 \mathrm{Al}-3 \mathrm{Cu}-1 \mathrm{Si}$ alaşımının sürtünme katsayısı, sıcaklık ve hacim kaybı değerleri büyük ölçüde azalmakta, yağ debisinin belirli bir değerin $\left(1 \mathrm{~cm}^{3} / \mathrm{saat}\right)$ üzerine çıkması durumunda ise bu parametreler fazla değişmemektedir. Basıncın artması durumunda Zn-15Al3Cu-1Si alaşımının sürtünme katsayısı azalmakta, aşınma ile meydana gelen hacim kaybı ve çalışma sıcaklığı değerleri ise artmaktadır. Kayma hızının artması durumunda Zn-15Al$3 \mathrm{Cu}-1 \mathrm{Si}$ alaşımı ve SAE 660 bronzuna ait aşınma numunelerinin yalnız sıcaklığ 1 artmakta, sürtünme katsayısı ve hacim kaybı değerleri ise fazla değişmemektedir.

Belirtilen deney koşullarında oluşan sürtünme 1sıs1, yüzey basıncı ve yüzey altı kayma gerilmelerinin yeterli düzeye ulaşamamaları nedeniyle aşınma numunelerinin içyapı ve sertliğinde belirgin bir değişim meydana gelmemektedir. Zn15Al-3Cu-1Si alaşımı, seçilen deney koşullarında SAE 660 bronzundan daha yüksek aşınma direnci sergilemektedir.

\section{TEŞEKKÜR (ACKNOWLEDGEMENT)}

$\mathrm{Bu}$ çalışma Karadeniz Teknik Üniversitesi Bilimsel Araştırmalar Birimi tarafından desteklenmiştir. (Kod No: 2008.112.03.2).

\section{KAYNAKLAR (REFERENCES)}

1. Gervais E., Levert H., Bess M., The Development of a Family of Zinc-Based Foundry Alloys, Trans. Am. Foundrym. Soc., 88, 183-194, 1980. 
2. Goodwin F.E. ve Ponikvar A.L., Engineering Properties of Zinc Alloys, International Lead Zinc Research Organization, A.B.D., 1989.

3. Lee P.P., Savaşkan T., Laufer E., Wear Resistance and Microstructure of Zn-Al-Si and Zn-Al-Cu Alloys, Wear, 117, 79-89, 1987.

4. Prasad B.K., Effects of Silicon Addition and Test Parameters on Sliding Wear Characteristics of ZincBased Alloy Containing 37.5\% Aluminium, Mater. T. JIM., 38 (8), 701-706, 1997.

5. Prasad B.K., Sliding Wear Response of a Zinc-based Alloy and its Composite and Comparison with a Gray Cast Iron: Influence of External Lubrication and Microstructural Features, Mat. Sci. Eng. A-Struct., 392, 427-439, 2005.

6. Savaşkan T., Alemdağ Y., Effects of Pressure and Sliding Speed on the Friction and Wear Properties of Al40Zn-3Cu-2Si Alloy: A Comparative Study with SAE 65 Bronze, Mat. Sci. Eng. A-Struct., 496, 517-523, 2008.

7. Skenazi A.F., Pelerin J., Coutsouradis D., Magnus B., Meeus M., Some Recent Developments in the Improvement of the Mechanical Properties of Zinc Foundry Alloys, Metallwissenschaft Tech. 37(9), 898902, 1983.

8. Aybarç U., Kara A., Çubuklusu H.E., Çe Ö.B., Effect of Hot Isostatic Pressing on Metallurgical and Mechanical Properties of A356 Alloy, Journal of the Faculty of Engineering and Architecture of Gazi University, 32 (4), 1327-1335, 2017.

9. Türk A., Kurnaz C., Şefik H., Comparison of the Wear Properties of Modified ZA-8 Alloys and Conventional Bearing Bronze, Mater. Design, 28, 1889-1897, 2007.

10. Özek C., Taşdemir V., Experimental Investigation of the Effects of Blank Holder Force and Die Surface Angle on the Warm Deep Drawing of AA5754-O Alloy, Journal of the Faculty of Engineering and Architecture of Gazi University, 32 (1), 171-179, 2017.

11. Gulbransen E.A., The Kinetics of Oxide Film Formation on Metals and Alloys, Transactions of the Electrochemical Society, 91, 573-604, 1947.

12. Hekimoğlu A.P., Savaşkan T., Effects of Contact Pressure and Sliding Speed on Unlubricated Friction and Wear Properties of Zn-15Al-3Cu-1Si Alloy, Tribol. T., 59 (6), 1114-1121, 2016.

13. Savaşkan T., Murphy S., Mechanical Properties and Lubricated Wear of Zn-25 Al Based Alloys, Wear, 116, 221-224, 1987.

14. Köster W., Moeller K., The Constitution and Volume Changes of $\mathrm{Zn}-\mathrm{Cu}-\mathrm{Al}$ Alloys. V. The Division of the Ternary Phases at Low Temperatures, Z. Metallkd., 34, 206-207, 1942.

15. Savaşkan T., Hekimoğlu A.P., Effect of quench-ageing treatment on the microstructure and properties of $\mathrm{Zn}$ -
15Al-3Cu alloy, Int. J. Mater. Res., 106 (5), 481-487, 2015.

16. Savaşkan T., Purçek G., Hekimoğlu A.P., Effect of copper content on the mechanical and tribological properties of ZnAl27-based alloys, Tribol. Lett., 15 (3), 257-263, 2003.

17. Hekimoğlu A.P., Savaşkan T., Effects of T5 and T6 heat treatments on the microstructure and mechanical properties of $\mathrm{Zn}-15 \mathrm{Al}-3 \mathrm{Cu}$ alloy, The International Conference on Material Science and Technology in Cappadocia, Nevşehir, 849-853, 6-8 Nisan, 2016.

18. Hekimoğlu A.P., Savaşkan T., Structure and mechanical properties of Zn-(5-25) Al alloys, Int. J. Mater. Res., 105 (11), 1084-1089, 2014.

19. Hekimoğlu A.P., Savaşkan T., Lubricated friction and wear properties of $\mathrm{Zn}-15 \mathrm{Al}-(1-5) \mathrm{Cu}$ Alloys, Turk J Electrom. Energ., 1 (2), 1-7, (2016).

20. Savaşkan T., Hekimoğlu A.P., Microstructure and mechanical properties of $\mathrm{Zn}-15 \mathrm{Al}$-based ternary and quaternary alloys, Mat. Sci. Eng. A-Struct., 603, 52-57, 2014.

21. Savaşkan T., Hekimoğlu A.P., Relationships between mechanical and tribological properties of $\mathrm{Zn}-15 \mathrm{Al}-$ based ternary and quaternary alloys, Int. J. Mater. Res., 107 (7), 646-652, 2016.

22. Savaşkan T., Hekimoğlu A.P., Pürçek G., Effect of Copper Content on the Mechanical and Sliding Wear Properties of Monotectoid-Based Zinc-AluminiumCopper Alloys, Tribol. Int., 37, 45-50, 2004.

23. Savaşkan T., Bican O., Effects of Silicon Content on the Microstructural Features and Mechanical and Sliding Wear Properties of Zn-40Al-2Cu-(0-5)Si Alloys, Mat. Sci. Eng. A-Struct., 404, 259-269, 2005.

24. Bican O., Savaşkan T., Influence of Test Conditions on the Lubricated Friction and Wear Behaviour of Al25Zn-3Cu Alloy, Tribol. Lett., 37, 175-182, 2010.

25. Bhushan B., Principles and Applications to Tribology, Wiley \& Sons Ltd., New York, A.B.D., 2013.

26. Persson B.N.J., Sliding Friction: Physical Principles and Applications, Springer, Berlin, Germany, 2000.

27. Mondal D.P., Das S., Rajput V., Effect of Zinc Concentration and Experimental Parameters on High Stress Abrasive Wear Behaviour of Al-Zn Alloys: A Factorial Design Approach, Mat. Sci. Eng. A-Struct., 406, 24-33, 2005.

28. Murphy S., Savaşkan T., Comparative Wear Behaviour of $\mathrm{Zn}-\mathrm{Al}$ Based Alloys in an Automotive Engine Application, Wear, 98, 151-161, 1984.

29. Savaşkan T., Pürçek G., Murphy S., Sliding Wear of Cast Zinc-Based Alloy Bearing under Static and Dynamic Loading Conditions, Wear, 252, 693-703, 2002.

30. Halling J., Principles of Tribology, Macmillan Education Ltd., Great Britain, 1989. 